\title{
O Processo de Aprendizagem de Alunos de Turismo e Hotelaria Sob a Perspectiva Andragógica
}

\author{
The Learning Process of Students of Tourism and Hospitality under the \\ Perspective Andragogical
}

\section{El Proceso de Aprendizaje de Los Estudiantes de Turismo y Hospitalidad Bajo la Perspectiva Andragógico}

\author{
Jammilly Mikaela Fagundes Brandão ${ }^{1}$ \\ Erica Dayane Chaves Cavalcante ${ }^{2}$ \\ Joelma Abrantes Guedes Temoteo ${ }^{3}$
}

\begin{abstract}
Resumo: Crianças, adolescentes e adultos possuem modos diferenciados de aprender, tornando necessária a utilização de abordagens específicas em seus processos de aprendizagem. Considerando o nível de maturidade e autodirecionamento que os adultos tendem a possuir na medida em que vão se desenvolvendo e vivenciando experiências, percebeu-se a necessidade de uma abordagem que considerasse essas diferenças individuais no processo de aprendizagem, fazendo emergir a andragogia - a arte e a ciência destinada a auxiliar os adultos a aprender e a compreender o processo de aprendizagem. Com efeito, este estudo tem como objetivo central analisar a percepção dos discentes de turismo e hotelaria sobre sua atuação em seu processo de aprendizagem, tendo como base o modelo andragógico desenvolvido por Knowles, Holton e Seanson (2011). Buscou-se verificar o perfil de discentes de cursos de bacharelado em turismo e hotelaria e analisar o nível de autodirecionamento (autonomia e independência) desses alunos em seu processo de aprendizagem com base nos princípios andragógicos. Como procedimentos metodológicos, realizou-se uma pesquisa survey com 60 discentes dos cursos de hotelaria e turismo da Universidade Federal da Paraíba - UFPB, utilizando como instrumento uma escala de 5 pontos que versava sobre a concordância desses alunos em relação aos itens. Os dados foram analisados a luz da teoria base. Como resultados, evidencia-se que os alunos que participaram desta pesquisa possuem, na percepção dos mesmos, características como autonomia, autodirecionamento e apresentam níveis de independência enquanto sujeitos em processo de formação e de desenvolvimento de competências, o que revela a necessidade de repensar a formação profissional para melhor aproveitar essas características. Por
\end{abstract}

1 Universidade Federal da Paraíba Professora do Departamento de Turismo e Hotelaria - DTH/UFPB. Mestre em Administração, pelo Programa de Pós-Graduação em Administração - PPGA/UFPB. Graduada em Administração e Hotelaria, pela UFPB. E-mail: jammillybrandao@hotmail.com

2 Universidade Federal da Paraíba Mestranda em Administração (PPGA-UFPB). Bacharel em Hotelaria (UFPB). E-mail: ericachaves.p@gmail.com.

3 Universidade Federal da Paraíba Mestre em Desenvolvimento e Meio Ambiente pelo PRODEMA/UFPB (2005). Pósgraduada em Turismo de Base Local pela UFPB. Graduada em Turismo e em Comunicação Social pela UFPB (2002). Professora Assistente do Departamento de Turismo e Hotelaria - DTH/UFPB. E-mail: joelma.abrantes@gmail.com. 
fim, destaca-se a importância da utilização de uma metodologia de ensino que possibilite abertura para os alunos adequarem seu processo de aprendizagem a sua forma particular de estudar e aprender.

Palavras-chave: Aprendizagem; Andragogia. Ensino Superior; Turismo; Hotelaria

\begin{abstract}
Children, teenagers and adults have different ways of learning to use specific approaches in their learning processes, making it necessary .Considering the level of maturity and self-direction that adults tend to have in that it will be developing and living experiences, we realized the need for an approach to consider these individual differences in the learning process, giving rise to andragogy - the art and science aimed at helping adults to learn and understand the process of learning. Indeed, this study is mainly aimed to analyze the perceptions of tourism and hospitality students about his role in their learning process, based on the andragogical model developed by Knowles, Holton and Seanson (2011). We sought to investigate the profile of students of bachelor degree in tourism and hospitality and analyze the level of self-directedness (autonomy and independence) of these students in their learning process based on andragogical principles. The methodological procedures, carried out a survey with 60 students of hospitality and tourism courses at the Federal University of Paraíba - UFPB, using as a scale of 5 points that dealt with these students assimilate the agreement in relation to the items. Data base theory of light were analyzed. As results, it is evident that students who have participated in this research, the perception thereof, characteristics such as autonomy, self-direction and present levels of independence as subjects in training and skills development process, which shows the need to rethink vocational training to better leverage these features. Finally, we highlight the importance of using a teaching method that allows students to opening suit your learning process to their particular way to study and learn.
\end{abstract}

Keywords: Learning; Andragogy; Adults Education; Tourism. Hospitality.

Resumen: Niños, adolescentes y adultos tienen diferentes maneras de aprender a usar enfoques específicos en sus procesos de aprendizaje, por lo que es necesario. Teniendo en cuenta el nivel de madurez y auto-dirección que los adultos tienden a tener ya que será el desarrollo y experiencias de vida, nos dimos cuenta de la necesidad de un enfoque de considerar estas diferencias individuales en el proceso de aprendizaje, dando lugar a la andragogía - el arte y la ciencia dirigido a ayudar a los adultos a aprender y comprender el proceso de aprendizaje. De hecho, este estudio tiene como objetivo principal analizar las percepciones de los estudiantes de turismo y hostelería sobre su papel en el proceso de aprendizaje, basado en el modelo andragógico desarrollado por Knowles, Holton y Seanson (2011). Hemos tratado de investigar el perfil de los estudiantes de licenciatura en turismo y hotelería y analizar el nivel de autodirección (autonomía e independencia) de estos estudiantes en su proceso de aprendizaje basadas en principios andragógicos. Los procedimientos metodológicos, llevaron a cabo una encuesta con 60 alumnos de los cursos de hostelería y turismo de la Universidad Federal de Paraíba - UFPB, utilizando como una escala de 5 puntos que se ocupan de estos estudiantes asimilar el acuerdo en relación con los artículos. Se analizó la teoría de base de datos de la luz. Como resultado, es evidente que los estudiantes que han participado en esta investigación, la percepción de los mismos, las características tales como la autonomía, la auto-dirección y los niveles actuales de la independencia como sujetos en proceso de desarrollo de la formación y habilidades, lo que demuestra la necesidad de repensar formación profesional para aprovechar mejor estas características. Por último, destacamos la importancia de utilizar un método de enseñanza que permite a los estudiantes para la apertura de su proceso de aprendizaje traje a su particular forma de estudiar y aprender.

Palabras clave: Aprendizaje; Andragogía; Educación Superior; Turismo; Hospitalidad 


\section{INTRODUÇÃO}

Nas instituições de ensino superior é comum encontrar o que Paulo Freire denomina como "educação depositária", ou seja, um sistema de imposição de conteúdos e de conhecimentos, avaliações e cobranças autoritárias em que o professor é detentor máximo do saber e o aluno um recipiente em que se deposita conteúdos programáticos (Freire, 1987). Como o aluno de graduação, geralmente, não é percebido como um aprendiz adulto (um ser autodirecionado e responsável pela própria vida) é comum a oferta de um ensino inadequado, embasado em pressupostos que não se aplicam à educação de adultos, ou seja, ao invés da aplicação de práticas de ensino alinhadas ao perfil desses alunos é predominante a utilização de abordagens pedagógicas, limitando a aprendizagem e, consequentemente, a formação profissional dos alunos.

Como as crianças e adultos possuem modos diferenciados de aprender, o planejamento e o desenvolvimento do processo de aprendizagem devem considerar as especificidades individuais do aprendiz. Considerando o nível de maturidade e autodirecionamento que os adultos tendem a possuir na medida em que vão se desenvolvendo e vivenciando experiências, percebeu-se a necessidade de uma abordagem que considerasse essas diferenças individuais no processo de aprendizagem, fazendo emergir a andragogia - a arte e a ciência destinada a auxiliar os adultos a aprender e a compreender o processo de aprendizagem (Knowles, 1975).

Partindo desse ponto, o enfoque central desse estudo envolve o processo de aprendizagem e a formação do turismólogo e hoteleiro, com base nos princípios centrais da andragogia desenvolvida por Knowles, Horton \& Swanson (2011). Com este estudo se busca ampliar a compreensão da necessidade de identificar o perfil do aluno e alinhar as estratégias de ensino a essas características individuais, de modo que esses possam vivenciar experiências significativas e transformadoras, e, assim, otimizar o processo de formação profissional. Sob essa perspectiva, essa pesquisa busca responder a seguinte questão: Como os discentes de turismo e hotelaria se percebem frente ao seu processo de aprendizagem?

O objetivo principal deste trabalho é analisar a percepção dos discentes de turismo e hotelaria sobre sua atuação em seu processo de aprendizagem, tendo como base o modelo andragógico desenvolvido por Knowles, Holton e Seanson (2011), que incluem: i - necessidade de saber do aprendiz, ii - conceito de si do aprendiz, iii - experiência prévia do aprendiz, iv - prontidão para aprender, $v$ - orientação para aprendizagem, vi - motivação para aprender.

No referencial teórico é retomada a apresentação do modelo andragógico desenvolvido por Knowles, Holton \& Seanson (2011), seguindo pelo processo de aprendizagem no ensino superior em turismo e hotelaria que é discutido a partir desses princípios. É importante colocar ainda que a escolha do tema para esta pesquisa resultou do interesse em investigar e contribuir em âmbito social, prático e acadêmico no que se refere à aprendizagem e à formação na área de turismo e hotelaria.

Em termos de contribuição científica, observou-se através de uma Revisão Sistemática da Literatura (RSL) nacional desenvolvida para retratar um panorama geral de trabalhos que exploram os temas "Educação de adultos" e "Autoaprendizagem" que são poucos os estudos que 
abordam estratégias instrucionais de ensino alinhadas à abordagem andragógica; que dê atenção aos objetivos e propósitos para o aprendizado e as particularidades contextuais, (incluindo as diferenças individuais e situacionais) e aos princípios andragógicos. A RSL consistiu na análise dos artigos científicos publicados entre os anos de 2003 e 2012, na base de periódicos Scielo.org, disponível no Portal de Periódicos da CAPES. No total foram analisados 124 artigos. Smith (2002) destaca que embora muitas pesquisas já tenham sido realizadas, ainda é um desafio saber como os sujeitos aprendem.

Além da contribuição teórica, este estudo se mostra relevante pelo seu potencial de contribuição prática e social. Reflexões sobre o perfil do aluno de graduação em turismo e hotelaria, assim como analisar o nível de autodirecionamento (autonomia e independência) desses alunos em seu processo de aprendizagem, poderá contribuir para o desenvolvimento e aperfeiçoamento dos cursos ofertados nessa área e possibilitar impactos significativos na metodologia de ensino, como também, consequentemente, no processo de aprendizagem. A partir disso, melhorias no ensino e na formação do turismólogo e do hoteleiro poderão insurgir, possibilitando aos mesmos uma melhor atuação em seu posto de trabalho resultando em uma melhor prestação de serviço à sociedade.

\section{PROCESSO DE APRENDIZAGEM DE ADULTOS SOB A ÓTICA DA ANDRAGOGIA}

De acordo com Cavalcanti e Gayo (2005), existem diferenças significativas entre crianças e adultos, e essas diferenças também precisam ser levadas em consideração no contexto da aprendizagem. Na infância e na adolescência é comum que o aluno apresente maior grau de dependência, pouca experiência acumulada, e vivencie pressão social pelo desenvolvimento biológico e psicológico. Nessa primeira fase, busca-se a aprendizagem centrada no conteúdo em si, vinculado a uma aplicação futura e incerta dos conhecimentos adquiridos naquele momento.

Por outro lado, o aprendiz adulto desenvolve papéis sociais complexos, aplica o que aprende na sua realidade imediatamente e tem sua aprendizagem centrada na resolução de problemas. Assim, o aluno adulto se desprende da necessidade de controle por terceiros em seu processo de aprendizagem, dado que já ampliou sua capacidade de autodireção, assim como traz consigo experiências vivenciadas anteriormente. Compreendendo que essas diferenças geram implicações no processo de aprendizagem, Knowles (1975) e outros autores desenvolveram estudos que embasam uma diferenciação conceitual entre a pedagogia e andragogia, considerando esta última como a abordagem mais adequada à educação de adultos.

A andragogia busca auxiliar e compreender o processo de aprendizagem dos adultos (Ferraz; Lima \& Silva, 2004; Knowles, 1975). Refere-se a uma teoria cuja aprendizagem é centrada no aluno. Knowles (1980, p. 43) define a andragogia como "a arte e a ciência de ajudar adultos a aprenderem". Considerando que os adultos possuem necessidades individuais a serem alcançadas por meio do aprendizado, a andragogia se fundamenta em elementos como desenvolvimento da 
reflexão crítica, a aprendizagem por meio das experiências e a melhoria do ambiente de aprendizagem para facilitar a aquisição de conhecimentos e troca de experiências (Freire, 1987).

Conforme Mezirow (1991), as pessoas vão aprimorando seu aprendizado à medida que vão ganhando experiência e, assim, a aprendizagem é baseada na interpretação e exposição das experiências vivenciadas pelo indivíduo, que são determinantes para as suas ações, suas expectativas, seu bem estar e seu desempenho. No entanto, Dewey (1973) já considerava o aspecto experiencial em seus estudos ao ressaltar que os indivíduos vivem, experimentam e aprendem concomitantemente.

Aliada a importância das experiências está a relevância de características de autodirecionamento dos alunos. Entende-se por autodirecionamento o processo em que o próprio aprendiz é quem despende esforços para localizar os recursos necessários para a sua aprendizagem, assumindo um papel ativo nas experiências que possam contribuir para o seu crescimento, assim como no diagnóstico e na avaliação da construção desse processo (Cranton, 2006; Brookfield, 1986).

De modo geral, considera-se como adulto o indivíduo que tem maturidade suficiente para assumir a responsabilidade de seus atos perante a sociedade. Entretanto, como a maturidade humana apresenta uma complexidade na definição de seus limites, o conceito de adulto pode sofrer variações de uma cultura para outra. Buscando descrever o que é ser adulto, Knowles, Holton e Swanson (2011) afirmam que existem no mínimo quatro aspectos que o caracterizam como tal. Conforme os autores, um conceito mais abrangente e objetivo para o adulto necessita de contribuições de quatro áreas distintas do conhecimento: biologia, sociologia, psicologia e ciências jurídicas.

O adulto, em uma concepção biológica, é um indivíduo que alcançou a idade de reprodução. Sendo assim, um ser humano atinge a fase adulta após iniciar sua vida sexual e tem filhos. Considerando a esfera jurídica, o indivíduo chega à fase adulta ao atingir a idade que, conforme as leis em vigor, o permite votar, casar sem prévia autorização dos pais, dirigir veículos, etc. Assim, sob esta concepção, pode-se dizer que o indivíduo se torna adulto ao atingir a maior idade legal, ou seja, aos dezoito anos. Por outro lado, na concepção sociológica, a vida adulta está associada ao desempenho de alguns papéis sociais, ou seja, o adulto é aquele que trabalha em horário integral, que possui um cônjuge, que já se tornou pai ou mãe.

$\mathrm{Na}$ esfera da Psicologia, adulto é aquele que atingiu uma independência psíquica, que possui um autoconceito de ser responsável pela própria vida e de ser autodirecionado. No âmbito da andragogia, esses dois últimos conceitos são essenciais. Ambos começam a se desenvolver já no início da adolescência e crescem à medida que os indivíduos passam a frequentar a escola, que assumem responsabilidades, que passam a vivenciar experiências profissionais. Nesse sentido, de acordo com Knowles, Holton e Swanson (2011), o grau de dependência de um indivíduo varia de acordo com o seu desenvolvimento cronológico.

Na medida em que o indivíduo amadurece cronologicamente, o seu grau de dependência diminui, o que resulta em uma maior necessidade de desenvolver o autodirecionamento. Ao 
atingirem essa fase, a aprendizagem se torna mais significativa quando os alunos compreendem o motivo da precisão daquele aprendizado e se responsabilizam pela sua própria aprendizagem, há a utilização de estratégias de ensino e aprendizagem com enfoque nas experiências vivenciadas pelo o próprio aprendiz, há observância da necessidade de saber do indivíduo e a sua situação de vida, há a consciência de que o aprendizado se aplica às situações da vida real, ou seja, eles conseguem perceber que podem aprender um novo conteúdo, que a aprendizagem desse novo conteúdo ajudará a resolver problema e que são importantes na sua vida. Assim, a abordagem que se apresenta mais apropriada a ser utilizada no processo de aprendizagem de adultos é a andragógica. A seguir será apresentado o modelo andragógico e seus princípios, considerados relevantes neste estudo.

\subsection{O Modelo Andragógico de Knowles, Holton e Swanson (2011)}

Levando em consideração que a aprendizagem é facilitada quando o aluno participa responsavelmente do seu processo de aprendizagem (Rogers, 1969), o modelo andragógico proposto por Knowles, Holton e Swanson (2011) pode ser visualizado como uma adequação necessária na educação para atender ao novo contexto da sociedade contemporânea.

Este modelo na prática consiste em três dimensões: (a) objetivos e propósitos para o aprendizado, que podem consistir no crescimento individual, institucional ou social; (b) as diferenças individuais e situacionais, considerando as particularidades contextuais no momento da escolha da estratégia de aprendizagem (c) e os princípios andragógicos, que compreendem a necessidade de saber do aprendiz, o autoconceito do aprendiz (aprendizagem autodirecionada), a experiência prévia, a prontidão para aprender, a orientação para a aprendizagem, e a motivação para aprender.

No primeiro princípio referente à necessidade de saber do aprendiz, os autores destacam que os adultos precisam compreender o motivo da precisão daquele aprendizado antes de começarem a de fato aprender. Para Carl Rogers (1969), a aprendizagem é significativa quando o aluno percebe a relevância do que será aprendido. Evidencia-se, ainda, que quando a decisão por aprender algo parte do próprio indivíduo, há um investimento maior de esforço tanto nos benefícios da aprendizagem, como nas consequências negativas da não-aprendizagem. Logo, o facilitador da aprendizagem de adultos tem como atividade primária ajudar os aprendizes a se conscientizarem da necessidade de aprender.

A necessidade de saber compreende três dimensões: a compreensão de como a aprendizagem será conduzida, o que será aprendido, e porque o aprendizado é importante. Assim, faz-se necessário conhecer as expectativas e desejos dos adultos, bem como o que proporciona maior comprometimento nesses aprendizes; demonstrar com antecedência o que será abordado, os resultados esperados e a liberdade de escolha em fazer ou não o curso, gerando assim maior comprometimento e satisfação na aprendizagem; e demonstrar a utilidade do aprendizado para a vida pessoal ou profissional do aprendiz (Knowles; Holton \& Swanson, 2011). 
O segundo princípio da andragogia se refere ao autoconceito do aprendiz quanto à responsabilidade de suas ações e decisões. Conforme Knowles, Holton e Swanson (2011), quando o aprendiz desenvolve esse autoconceito ele vai perdendo a necessidade de reconhecimento por terceiros e se mostra resistente a situações de imposição. A auto-aprendizagem é uma maneira de aprender em que o aluno por meio de iniciativa própria se responsabiliza pela sua aprendizagem, ao invés de esperar que terceiros determinem o que e como ele irá aprender (Merriam; Caffarella \& Baumgartner, 2006; James-Gorndon \& Bal, 2003).

Há duas concepções de aprendizagem autodirigida predominantes na literatura: uma referente à autoaprendizagem, que considera a capacidade dos alunos assumirem o controle do seu processo de aprendizagem de modo independente e outra que se refere a autonomia pessoal, que consiste na autodidática do aprendiz em exercer o controle dos objetivos e propósitos de aprendizagem (Knowles; Horton \& Swanson, 2011). Para Chene (1983), aprendizes autônomos são aqueles indivíduos independentes, com capacidade de fazer suas próprias escolhas e com capacidade de articular as normas e limites de uma atividade de aprendizagem. Além desses elementos, considera-se ainda como atributos de um aprendiz autônomos a confiança, o compromisso, o sentido de autodirecionamento e a reflexão crítica (Candy, 1987; Brookfield, 1986; Mezirow, 1985). No entanto, cabe ressaltar que a autonomia do aprendiz depende do contexto: em certas situações de aprendizagem o indivíduo consegue ser autônomo e em outras não (Candy, 1991).

O terceiro princípio andragógico envolve o papel das experiências do aprendiz em seu processo de aprendizagem. Sobre esse aspecto, considera-se que devido os adultos terem vivenciado um número maior e diversificado de experiências (Merriam; Caffarella \& Baumgartner, 2006; Kolb, 1984), a educação de adultos deve utilizar estratégias de ensino e aprendizagem com um enfoque na individualização, ou seja, em que o próprio aprendiz é um recurso de aprendizagem, sendo necessário utilizar técnicas como discussões de grupo, exercício de simulação, atividades que envolvam resolução de problemas, estudos de casos, entre outras que explorem a própria experiência do aprendiz (Knowles; Horton \& Swanson, 2011).

As experiências do adulto geram impactos na sua aprendizagem, uma vez que criam uma diversidade de diferenças individuais, fornecem um rico recurso para a aprendizagem, geram conceitos prévios que tanto podem inibir como facilitar uma nova aprendizagem e fornecem uma base para a autoidentidade do adulto. Merriam, Caffarella \& Baumgartner (2006) observam que as pessoas carregam um conjunto de esquemas que refletem as suas experiências, denominado por Kolb (1984) como os "reservatórios de experiências" ou "loja de lembranças na mente", sendo esse a base para assimilar novas informações. De acordo com Kolb (1984), quando o reservatório de experiências do aprendiz é insuficiente para solucionar seus problemas diários, eles desenvolvem uma necessidade de aprender para que possam em seguida colocar esse novo aprendizado em prática.

É importante observar que essa bagagem experiencial pode contribuir para a efetividade da aprendizagem, mas também pode se refletir de modo negativo, caso o adulto desenvolva 
hábitos mentais ou predisposições que o tornem resistente a novos modelos e abordagens (Schön, 1987; Argyris, 1982). Ao perceber esse conflito, é responsabilidade do educador desenvolver maneiras que ajudem esse aprendiz a reavaliar sua postura, assim como auxiliá-lo para a aceitabilidade de novas abordagens (Knowles; Horton \& Swanson, 2011). Nesse caso, o processo de "desaprender" é tão importante quanto o processo de aquisição de um novo aprendizado.

O quarto princípio andragógico diz respeito à prontidão do adulto para aprender. Esta prontidão se relaciona à necessidade de saber do indivíduo e a sua situação de vida. Assim, defende-se o pressuposto de que quanto mais os educadores entenderem sobre a situação de vida e a prontidão para aprender de seus alunos, mais efetiva será a aprendizagem. Todavia, destaca-se a característica situacional da aprendizagem, cujo aprendiz pode ter diferentes comportamentos em diferentes momentos do processo de aprendizagem, podendo em algumas situações se apresentar autodirecionado e em outras, dependente. Em outras palavras, há variações do grau de dependência, que reflete na alta ou baixa necessidade de direção e suporte.

O termo direção trata da necessidade de assistência por outra pessoa no processo de aprendizagem; e suporte faz referência ao apoio afetivo que ela espera receber dos outros (Knowles; Holton \& Swanson, 2011). Conforme os autores, há muitos fatores que influenciam na posição de autodirecionamento dos indivíduos em determinadas situações, dentre esses estão: seu estilo de aprendizagem, suas experiências anteriores com o assunto específico, sua orientação social, seu processo de socialização na aprendizagem anterior, e o lócus de controle.

O quinto princípio da andragogia trata da orientação para aprendizagem dos adultos estar voltada à solução de problemas. Os adultos se sentem motivados a aprender quando percebem que o aprendizado irá ajudá-los na resolução de um problema, na execução de uma tarefa ou lidar com as situações diárias. Acredita-se que a aprendizagem se torna mais significativa quando o aprendizado se aplica às situações da vida real. A partir disso, a abordagem experiencial passou a ser considerada fundamental na prática da aprendizagem de adultos (Knowles; Holton \& Swanson, 2011; Jarvis, 2006; Kolb, 1984).

O conceito central da aprendizagem pela experiência é a própria experiência do indivíduo, ou seja, todo o arcabouço aprendido por ele ao longo da vida fará com que ele desenvolva novos conhecimentos a partir de suas vivências anteriores (Knowles; Holton \& Swanson, 2011). Kolb (1984) é considerado um líder na prática da aprendizagem experiencial. Conforme o autor, o conhecimento passa a ser desenvolvido no momento em que o indivíduo participa e vivencia experiências. Ao observar e refletir sobre essas experiências, criam-se conceitos, ligando-os as teorias. Por fim, aplicam-se os novos conhecimentos na prática em suas tomadas de decisões e resoluções de problemas. Esse modelo tem se mostrado valioso para o desenho de experiências de aprendizagem de adultos, sendo utilizados na estruturação de cursos e disciplinas, assim como, incluídos em unidades do conteúdo ou atividades.

Por fim, o último princípio andragógico se refere à motivação para aprender. Defende-se no modelo andragógico de Knowles, Holton e Swanson (2011) que devido a pressões internas como o desejo de aumentar a satisfação no trabalho, de maximizar a auto-estima e melhorar a 
qualidade de vida, o aprendiz adulto se apresenta mais motivado para aprender. Embora não se desconsidere às motivações externas como uma melhor opção de emprego, aumento salarial, promoção de cargo, entre outros, evidencia-se que, no adulto, as motivações internas são as mais significativas.

Knowles, Horton e Swanson (2011), baseando-se em autores como Wlodowski (1985), define que o que move um aprendiz adulto a se motivar para aprender é a soma de quatro fatores: (1) ter sucesso na aprendizagem; (2) ter a sensação de que está aprendendo aquilo que ele mesmo escolheu aprender; (3) buscar aprender algo que ele valoriza; e (4) a aprendizagem é vista como uma experiência de prazer.

A teoria da expectativa de Vroom (1995) tratada como a teoria clássica da motivação de adultos no ambiente de trabalho se baseia em três fatores: (1) o valor colocado no resultado; (2) a probabilidade de que os resultados serão alcançados, dado que certos resultados aconteçam; e (3) a crença que uma pessoa tem de que um determinado esforço levará a resultados que serão recompensadores. Nesse sentido, Knowles, Holton e Swanson (2011) concluíram que os adultos ficam mais motivados quando acreditam que podem aprender um novo conteúdo, que a aprendizagem desse novo conteúdo ajudará a resolver problema e que são importantes na sua vida.

O desenvolvimento de capacidades de aprendizagem autodirecionada parece ser um dos principais objetivos no âmbito da educação de adultos, (Knowles, Holton \& Swanson, 2011; Brookfield, 1986). Inseridos em um contexto de intensas e imprevistas transformações passou a ser necessário aos indivíduos o desenvolvimento de capacidades que os levem a evoluir e a agir de maneira autônoma, passando a exigir do aprendiz que esse seja capaz de conduzir sua educação e aprender de modo independente (Couceiro, 1995; Candy, 1991). Com base nisso, destaca-se a importância de promover no ensino superior condições libertadoras para impulsionar a autonomia e o autodirecionamento nos alunos universitários, em especial, os graduandos em turismo e hotelaria.

\section{A EDUCAÇÃO SUPERIOR EM TURISMO E HOTELARIA}

O curso de turismo visa a formar profissionais aptos a atuarem em cargos gerenciais (diretivos e executivos) em organizações na grande área de turismo. O ensino superior de turismo passou a ser ofertado no Brasil na década de 1970. Após cinco décadas de existência do referido curso, há um número considerável de formados na área. De modo similar, o curso de hotelaria visa a preparar para a atuação em sistemas hoteleiros e extra-hoteleiros, como assessor, gestor e consultor. Além de prepará-los para a promoção e participação da melhoria do processo de gestão e desenvolvimento das atividades hoteleiras, na busca do aumento da produtividade e competitividade. O Curso de hotelaria emerge no Brasil por meio do ensino profissionalizante para a área operacional, em 1950, sendo oferecido pelo Senac, que havia sido impulsionado por importantes mudanças sociais e econômicas na década anterior (Carneiro, 2002). A necessidade 
de profissionais especializados e o “(...) certo tom de modismo e glamour atribuídos aos cargos de chefia na administração hoteleira" estimularam jovens a buscarem esta formação, assim como o aparecimento de cursos na área (Carneiro, 2002, p. 31).

Nesse contexto, surge a necessidade de se refletir sobre a qualidade desses cursos e a formação do turismólogo e do hoteleiro no país. No Brasil existem centenas de cursos de turismo e Hotelaria, no entanto, grande parte deles não atingem o objetivo de propiciar uma formação sólida. Por se apresentarem como cursos deficitários, deixam de contribuir para o desenvolvimento do turismo no país (Brusadin, 2007). De acordo com Silva (2005), as instituições universitárias devem oferecer uma educação superior embasada na criticidade, consistindo em um lugar onde se discute e se projeta o rumo da sociedade e suas relações com a globalização. 0 mesmo deve acontecer no ensino superior em turismo e hotelaria.

$\mathrm{O}$ aluno universitário pode ser considerado como um aluno adulto, à medida que se observa que, em geral, tratam-se de pessoas com idade próxima ou acima de 18 anos e já desempenham alguns papéis sociais (trabalham, vivenciam uma vida a dois com um cônjuge, já se tornaram pai ou mãe). De acordo com Knowles, Holton e Swanson (2011) alunos com esse perfil, devido à vivência de experiências profissionais e sociais, possuem maior autonomia, independência, autodirecionamento e maturidade no processo de aprendizagem. No entanto, embora os alunos universitários de turismo e de hotelaria apresentem esse perfil, surge uma reflexão: será que essas características são bem aproveitadas no processo de aprendizagem? Até que ponto a formação em turismo e hotelaria explora o poder reflexivo e a criticidade que esses aprendizes adultos possuem?

Um processo de formação, principalmente quando é voltado a alunos adultos, deve permitir que o aprendiz possa interferir no processo de aprendizagem com base nas suas necessidades e com liberdade de refletir e criticar (Freire, 2003). Tratando-se de um curso voltado à formação de turismólogos, esses aspectos merecem ainda mais atenção, tendo em vista que a reflexão e a criticidade são essenciais a esses profissionais no exercício de suas funções. Com efeito, sugere-se a promoção de condições libertadoras para impulsionar a autonomia e desenvolver um senso de auto-capacitação (Mezirow, 1991), pois só assim os alunos estarão aptos a interagir no meio social, compreender o mundo e interferir na realidade que os cercam (Freire, 1987).

\section{PROCEDIMENTOS METODOLÓGICOS}

Este estudo foi realizado em duas etapas. Na primeira foi empreendida uma revisão sistemática da literatura por meio de um levantamento bibliográfico nacional na base de periódicos Scielo.org disponível no Portal de Periódicos da CAPES. Dentre os artigos publicados entre 2003 e 2012, foram encontrados 371 ocorrências para as palavras-chave "Educação de adultos" e "Autoaprendizagem". Após a leitura dos títulos e resumos para identificar se os temas estavam alinhados a abordagem deste estudo, chegou-se a um total de 124 artigos $(33,4 \%$ do 
total), entretanto, nenhum deles estava na grande área do turismo. Estes achados foram importantes para indicar a relevância do tema, bem como situar os autores deste artigo em relação ao seu avanço no campo da administração, do turismo e da hotelaria. Na segunda etapa, para viabilizar a consecução dos objetivos, foi realizado um levantamento - survey. A pesquisa survey é descrita como o modo de obter informações de um grupo específico de pessoas representante de uma população em estudo - sobre suas características ou percepções, por meio da aplicação de um questionário como instrumento de pesquisa (Fonseca, 2002).

Este estudo teve como população-alvo alunos dos cursos de graduação em turismo e hotelaria da Universidade Federal da Paraíba - UFPB. O estudo foi realizado com os alunos da referida instituição por viabilidade e acessibilidade, dado que duas autoras deste estudo compõem o corpo docente do departamento de turismo e hotelaria da UFPB. Ainda pela questão da viabilidade, os alunos respondentes foram selecionados de forma aleatória entre os discentes dos cursos de turismo e hotelaria da UFPB. Participaram da pesquisa 60 discentes, sendo 30 pertencentes ao curso de turismo e 30 ao de hotelaria. Vale destacar que os questionários foram aplicados durante o mês de maio de 2014, em turnos distintos, considerando o horário das aulas de ambos os cursos: foram aplicados de dia aos discentes do curso de Hotelaria e à noite aos do curso de turismo.

Por tanto, para compreender a percepção dos discentes sobre sua postura frente aos princípios andragógicos que norteiam a aprendizagem, utilizou-se como técnica de coleta de dados uma escala de 5 pontos, com a variação: "1" a " 5 ", em que (5) e (4) se refere a alta concordância do discente; (3) a uma concordância moderada; e (2) e (1) a uma baixa concordância. Como mencionado, as categorias se referiam aos princípios da andragogia, e subcategorias elaboradas para explorar o entendimento de cada princípio, a saber: necessidade de saber do aprendiz, conceito de si, experiência prévia; prontidão para aprender; orientação para a aprendizagem; e motivação para aprender, de modo que o questionário foi composto por 25 questões. Adicionalmente, coletou-se os dados demográficos dos respondentes, uma vez que estes implicam diretamente na compreensão dos princípios.

Os dados foram tabulados no Excel e a análise dos dados foi realizada por interpretação dos dados, por meio da verificação da discordância à concordância dos discentes quanto às questões, diante a uma análise simples de frequência. Por fim, os resultados foram revistos a luz da teoria.

\section{APRESENTAÇÃO DOS RESULTADOS}

Esse estudo tem como objetivo central analisar a percepção dos discentes de turismo e hotelaria sobre sua atuação em seu processo de aprendizagem, tendo como base o modelo andragógico desenvolvido por Knowles, Holton e Seanson (2011). Com efeito, buscou-se verificar o perfil de discentes de cursos de bacharelado em turismo e hotelaria e analisar o nível de autodirecionamento (autonomia e independência) desses alunos em seu processo de 
aprendizagem com base nos princípios andragógicos. Nesse sentido, além das questões sóciodemográficas foram utilizadas assertivas referentes aos princípios andragógicos, solicitando aos participantes (alunos de cursos de turismo e hotelaria) que apontassem seu nível de concordância em uma escala de 1 a 5. Os resultados serão apresentados nas subseções a seguir.

\subsection{Perfil dos discentes}

Existem fatores mediadores associados ao perfil do aluno adulto, que tanto podem facilitar como dificultar os processos de aprendizagem. Assim, destaca-se a importância de compreender a interferência desses fatores na aprendizagem. Essa discussão é apresentada por autores como Silva (2009), Souza (2004), Silva, Godoi e Rambo (2003), Antonacopoulou e Gabriel (2001) e Merriam, Caffarella e Baumgartner (2006). Partindo desse ponto, ressalta-se a necessidade do alinhamento das estratégias de ensino às características individuais do aluno, de modo que esses possam vivenciar experiências significativas e transformadoras.

Entende-se que as experiências vivenciadas pelo aprendiz, sejam essas profissionais, sociais ou de educação formal, exercem influência na aprendizagem, podendo ser tanto propulsora quanto inibidora. Nesse sentido, o primeiro objetivo específico consistiu em verificar o perfil de discentes de cursos de bacharelado em turismo e hotelaria, partindo do pressuposto de que 0 conhecimento das características individuais do aluno é essencial para assegurar a qualidade do ensino e tornar a aprendizagem mais significativa.

Atendendo a esse objetivo, constatou-se que os discentes que participaram desta pesquisa eram, de modo equiparado, dos cursos de turismo (30) e de Hotelaria (30). A distribuição destes discentes por período se encontra disposta na Tabela 1:

Tabela 1 - Distribuição dos alunos respondentes por período

\begin{tabular}{|c|c|c|c|}
\hline & $13-1$ 1 período & & $05-1$ ㅇp período \\
\hline \multirow{5}{*}{ Turismo } & 08 - 2ํo período & & $03-2$ o período \\
\hline & 04 - 3o período & & $08-3$ o período \\
\hline & 03 - 4o período & Hotelaria & $08-4$ o período \\
\hline & 01 - 50 período & & $06-5$ o período \\
\hline & 01 - 8o período & & \\
\hline Total & 30 alunos & & 30 alunos \\
\hline
\end{tabular}

Fonte: Pesquisa (2014)

A maioria dos respondentes foi do gênero feminino (35), entre os 25 do gênero masculino. Estes possuíam idades distribuídas, em que grande maioria se encontrava no intervalo entre 17 e 20 anos (25) e entre 21 a 29 anos (26). Todavia, é válido mencionar que 09 discentes possuíam idades entre 30 a 51 anos em que biologicamente se pode afirmar um considerável nível de maturidade.

Quanto ao estado civil, a grande maioria dos discentes informou estar solteira (48), enquanto apenas 11 se encontram casados e 1 divorciado. A maioria informou ainda não ter filho (52), enquanto apenas 8 possuem filho. Apenas 1 discente informou ter outra formação superior. 
A maioria destes discentes não trabalha (42) e estes vivem, em grande maioria, com os pais (43). Apenas 1 discente informou viver sozinho.

No entanto, cabe ressaltar que embora se tenha verificado a predominância dessas categorias, foi observado que os alunos se alicerçam por distintos grupos sociais, possuem diferentes idades e compromissos familiares diversos e isso precisa ser considerado no planejamento das estratégias, dos métodos e recursos a serem utilizados nos cursos.

Compreender quem é o aluno universitário é o primeiro passo para tornar o ensino superior mais eficaz em seu propósito: educação embasada na criticidade, consistindo em um lugar onde se discute e se projeta o rumo da sociedade e suas relações com a globalização. Conhecer as características e necessidades dos alunos poderá aperfeiçoar a qualidade do ensino e, consequentemente, otimizar a formação dos futuros hoteleiros e turismólogos.

\subsection{Princípios Andragógicos na percepção dos Discentes e Reflexões Correlatas}

Buscando proporcionar uma melhor compreensão sobre o nível de autodirecionamento (autonomia e independência) desses alunos em seu processo de aprendizagem com base nos princípios andragógicos, os resultados foram agrupados em 6 categorias de análise.

A primeira categoria de análise é referente ao primeiro principio andragógico, na qual se buscou identificar como os alunos de turismo e hotelaria percebem a necessidade de saber. Sobre esse aspecto, buscou verificar se os alunos possuem consciência do que necessitam aprender; se conseguem perceber a relevância do que é ensinado para a sua vida pessoal; se conseguem perceber a relevância do que é ensinado para a sua vida profissional; se compreendem como a aprendizagem é conduzida; e se tiveram a liberdade de escolha e decisão em fazer o curso. Os dados correspondentes a esta categoria estão dispostos na Tabela 2:

Tabela 2 - Necessidade de aprender do aprendiz

\begin{tabular}{|c|c|c|c|}
\hline Categoria & $\begin{array}{l}\text { Concordância } \\
\text { baixa }\end{array}$ & Moderada & $\begin{array}{l}\text { Concordância } \\
\text { alta }\end{array}$ \\
\hline Consciência do que necessita aprender & 01 & 0 & 59 \\
\hline $\begin{array}{l}\text { Relevância do que é ensinado para a sua vida } \\
\text { pessoal }\end{array}$ & 10 & 0 & 50 \\
\hline $\begin{array}{l}\text { Relevância do que é ensinado para a sua vida } \\
\text { profissional }\end{array}$ & 0 & 07 & 53 \\
\hline Compreensão de como a aprendizagem é conduzida & 01 & 13 & 46 \\
\hline $\begin{array}{l}\text { Liberdade de escolha e decisão em fazer ou não o } \\
\text { curso }\end{array}$ & 04 & 04 & 52 \\
\hline
\end{tabular}

Fonte: Pesquisa (2014)

É possível observar que os futuros hoteleiros e turismólogos que participaram desta pesquisa, em sua maioria, possuem consciência do que necessitam aprender e percebem a relevância do que é ensinado em seus cursos de bacharelado tanto para a sua vida pessoal quanto profissional. Essa constatação demonstra que os conteúdos abordados no curso são relevantes e 
condizem com as práticas hoteleiras e turísticas. Além disso, a maioria dos alunos informou que compreende como a aprendizagem é conduzida e eles mesmos escolheram e decidiram em fazer o curso, o que é visto de maneira positiva, uma vez que de acordo com o primeiro princípio andragógico, esses aspectos tornam a aprendizagem mais significativa.

A segunda categoria de análise se refere ao segundo principio andragógico que enfatiza o conceito de si do aprendiz. Buscou-se verificar se os alunos de turismo e hotelaria se percebem como autônomos, independentes e autodirecionados em seu processo de aprendizagem. Esse princípio aponta características não só demandadas pela educação superior, mas também pelo mercado de trabalho (Knowles, Holton \& Swanson; 2011; Brokfield, 1986). Autonomia, capacidade de evoluir e agir de maneira autônoma, independência, responsabilidade, habilidade para solucionar problemas e comprometimento são características necessárias ao turismólogo e ao hoteleiro. Por tanto, desenvolvê-las e colocá-las em prática no processo de aprendizagem é considerado algo bastante positivo.

Nesse sentido, questionou-se se eles esperam que terceiros determinem o que eles vão e como vão aprender; se têm iniciativa em seu processo de aprendizagem, se possuem capacidade de evoluir e agir de maneira autônoma; se são independentes no processo de aprendizagem; se são responsáveis pela própria aprendizagem; se desenvolvem a programação dos seus estudos; se possuem habilidade para solucionar os problemas existentes no seu processo de aprendizagem; e se eles se consideram comprometidos com a própria aprendizagem. Os dados desta categoria estão dispostos na Tabela 3:

Tabela 3 - O conceito de si do aprendiz

\begin{tabular}{lccc}
\multicolumn{1}{c}{ Categoria } & $\begin{array}{c}\text { Concordância } \\
\text { baixa }\end{array}$ & Moderada & $\begin{array}{c}\text { Concordância } \\
\text { alta }\end{array}$ \\
\hline $\begin{array}{l}\text { Espera da determinação do que aprender e como } \\
\text { aprender }\end{array}$ & 35 & 13 & 12 \\
$\begin{array}{l}\text { Iniciativa no processo de aprendizagem } \\
\text { Capacidade de evoluir e agir de maneira autônoma }\end{array}$ & 04 & 06 & 50 \\
Independência no processo de aprendizagem & 06 & 10 & 44 \\
Responsabilidade pela própria aprendizagem & 26 & 15 & 19 \\
$\begin{array}{l}\text { Programação dos próprios estudos } \\
\text { Habilidade para solucionar os problemas existentes no }\end{array}$ & 15 & 14 & 31 \\
seu processo de aprendizagem & 08 & 21 & 32 \\
Comprometimento com a própria aprendizagem & & 20 & 52 \\
\hline
\end{tabular}

Fonte: Pesquisa (2014)

As constatações desse princípio também foram positivas já que estes alunos de turismo e hotelaria segundo suas próprias percepções têm iniciativa em seu processo de aprendizagem, possuem capacidade de evoluir e agir de maneira autônoma; são independentes e responsáveis pela própria aprendizagem; desenvolvem a programação dos seus estudos; possuem habilidade para solucionar os problemas existentes no seu processo de aprendizagem; e se consideram comprometidos com a própria aprendizagem. Surge então a necessidade de uma reflexão: Será que essas características estão sendo aproveitas no processo de aprendizagem? 
Fazer com que o aluno participe ativamente de todas as etapas do processo de aprendizagem (identificação das necessidades, planejamento das atividades, identificação dos recursos necessários, execução e avaliação das próprias experiências de aprendizagem); ou seja, assumir uma postura autodirecionada no processo de aprendizagem também deve ser uma demanda do ensino superior em turismo. Vale ressaltar que os alunos autodirecionados, isto é, que se envolvem com o seu processo de aprendizagem aprendem mais e se aprendem mais, possivelmente, serão profissionais mais preparados para a realização da sua profissão enquanto turismólogos e hoteleiros (Merriam, Caffarella \& Baumgartner, 2006; Cranton, 2006; Candy, 1987; Brookfield, 1986).

A terceira categoria de análise está relacionada ao princípio andragógico que se refere à experiência prévia do aprendiz. De acordo com Garrison (1992, p. 146) o aprendiz, para ser autodirigido, tem que ser "responsável por relacionar as novas ideias e a experiência com os conhecimentos já existentes bem como de partilhar esses novos conhecimentos em ordem a justificá-los e a validá-los". Para a análise desse princípio utilizou-se três assertivas buscando verificar se o aluno de turismo e hotelaria possuem maior facilidade de aprendizagem em atividades que explorem a sua própria experiência, tais como discussões de grupo, estudos de caso, etc; se eles se consideram abertos a novas abordagens e métodos de ensino; ou resistente a novos métodos e abordagens de ensino. Os dados desta categoria estão dispostos na Tabela 4:

Tabela 4 - Experiência prévia do aprendiz

\begin{tabular}{lccc}
\multicolumn{1}{c}{ Categoria } & $\begin{array}{c}\text { Concordância } \\
\text { baixa }\end{array}$ & Moderada & \multicolumn{2}{c}{$\begin{array}{c}\text { Concordância } \\
\text { alta }\end{array}$} \\
\hline $\begin{array}{l}\text { Facilidade de aprendizagem em atividades que } \\
\text { explorem a sua própria experiência }\end{array}$ & 04 & 14 & 42 \\
$\begin{array}{l}\text { Abertura a novas abordagens e métodos de ensino } \\
\text { Resistência a novas abordagens e métodos de ensino }\end{array}$ & 01 & 07 & 52 \\
\hline
\end{tabular}

Fonte: Pesquisa (2014)

Os dados referentes a esse princípio permitem concluir que os alunos de turismo e hotelaria, em sua maioria e conforme suas próprias percepções, são pessoas de baixa resistência, abertos a novos métodos e ferramentas de ensino em seu processo de aprendizagem. Destaca-se que estes alunos mesmo atingindo a fase adulta, ou seja, já possuindo autonomia e maturidade, ao vivenciar experiências de aprendizagem ao longo da sua vida estudantil embasadas na abordagem pedagógica acabam apresentando uma postura mais passiva no ensino superior. Essa bagagem experiencial muitas vezes dificulta o desenvolvimento de uma postura mais ativa e participativa em termos de direcionamento da aprendizagem. Para minimizar essa resistência, destaca-se a importância da utilização de uma metodologia que possibilite abertura para os alunos adequarem seu processo de aprendizagem a sua forma particular de estudar e aprender.

A quarta categoria de análise trata do princípio que se refere à prontidão para aprender. Nesse estudo se utilizou duas assertivas para analisar esse princípio: uma referente à necessidade de suporte, na qual se buscou verificar a necessidade de apoio afetivo de terceiros (pais, monitores, etc.) por parte dos alunos de turismo e hotelaria para aprender; e a necessidade de 
direção, ou seja, a necessidade de assistência por outra pessoa no processo de aprendizagem. Os dados relativos a esta categoria estão dispostos na Tabela 5:

Tabela 5 - Prontidão para aprender

\begin{tabular}{lccc}
\hline \multicolumn{1}{c}{ Categoria } & $\begin{array}{c}\text { Concordância } \\
\text { baixa }\end{array}$ & Moderada & $\begin{array}{c}\text { Concordância } \\
\text { alta }\end{array}$ \\
\hline $\begin{array}{l}\text { Necessidade de suporte (apoio afetivo de } \\
\text { terceiros) }\end{array}$ & 18 & 14 & 28 \\
Necessidade de direção & 13 & 16 & 31 \\
\hline
\end{tabular}

Fonte: Pesquisa (2014)

Verificou-se que os alunos de turismo e hotelaria revelaram que necessitam de suporte e direção no processo de aprendizagem. No entanto, o fato deles em determinados momentos apresentarem essas necessidades não significa que eles não possuam autodirecionamento. Cabe aqui reflexões aos agentes responsáveis pelo planejamento dos processos de aprendizagem (gestores, professores), para o desenvolvimento de estratégias e recursos que busquem minimizar essa fragilidade no ensino superior.

O fato do ensino ser superior e a aprendizagem ser autodirecionada não significa que o processo de aprendizagem tem que acontecer no isolamento. Ao contrário, é imprescindível a formação do turismólogo e hoteleiro que haja trocas de conhecimentos e experiências para que a aprendizagem seja significativa e transformadora. É pertinente ainda ressaltar que essa interação entre os alunos e o professor não anula o autodirecionamento.

A quinta categoria de análise está associada ao princípio andragógico referente à orientação para aprendizagem. Sobre esse aspecto, buscou-se identificar a percepção dos alunos sobre a relevância da aprendizagem. Assim, questionou-se se a aprendizagem é significativa quando ajuda na resolução de um problema; se a aprendizagem é significativa quando ajuda na execução de uma tarefa; e se a aprendizagem é significativa quando se aplica nas situações diárias. Em relação a esta categoria, os dados estão dispostos na Tabela 6:

Tabela 6 - Orientação para aprendizagem

\begin{tabular}{lccc}
\hline \multicolumn{1}{c}{ Categoria } & $\begin{array}{c}\text { Concordância } \\
\text { baixa }\end{array}$ & Moderada & $\begin{array}{c}\text { Concordância } \\
\text { alta }\end{array}$ \\
\hline $\begin{array}{l}\text { A aprendizagem é significativa quando ajuda na } \\
\text { resolução de um problema }\end{array}$ & 02 & 09 & 49 \\
$\begin{array}{l}\text { A aprendizagem é significativa quando ajuda na } \\
\text { resolução de um problema }\end{array}$ & 01 & 06 & 53 \\
$\begin{array}{l}\text { A aprendizagem é significativa quando ajuda na } \\
\text { execução de uma tarefa; e se a aprendizagem é } \\
\text { significativa quando se aplica nas situações diárias }\end{array}$ & 0 & 08 & 52 \\
\hline $\begin{array}{l}\text { Fonte: Pesquisa (2014) } \\
\text { (20) }\end{array}$ & &
\end{tabular}

Observa-se que os alunos de turismo e hotelaria associam a utilidade da aprendizagem a sua aplicação na resolução de um problema, na execução de uma tarefa e nas situações diárias, corroborando o que os autores da aprendizagem de adultos enfatizam. Logo, faz-se necessário 
uma abordagem de ensino que explore mais as experiências dos alunos e mais uma vez se destaca a importância das associações do conteúdo teórico com a prática (Rogers, 2011; Knowles, Holton \& Swanson, 2011; Dewey, 1973).

A sexta categoria de análise buscou analisar a motivação para aprender dos alunos de turismo e hotelaria. Nesse sentido, questionou-se se os alunos se sentem motivados quando acreditam que a aprendizagem desse novo conteúdo os ajudará a resolver problemas; se se sentem motivados quando acreditam que a aprendizagem é importante suas vidas; se sentem motivados quando reconhecem a importância do conteúdo que aprendem; e se sentem motivados quando o processo de aprendizagem possibilita uma experiência prazerosa. Os resultados se encontram organizados na Tabela 7:

Tabela 7 - Motivação para aprender

\begin{tabular}{lccc}
\multicolumn{1}{c}{ Categoria } & $\begin{array}{c}\text { Concordância } \\
\text { baixa }\end{array}$ & Moderada & $\begin{array}{c}\text { Concordância } \\
\text { alta }\end{array}$ \\
\hline $\begin{array}{l}\text { Motivação quando acreditam que a aprendizagem } \\
\text { desse novo conteúdo os ajudará a resolver } \\
\text { problemas }\end{array}$ & 0 & 9 & 51 \\
$\begin{array}{l}\text { Motivação associada à percepção da importância } \\
\text { da aprendizagem para sua vida } \\
\text { Motivação associada ao reconhecimento da }\end{array}$ & 0 & 4 & 56 \\
$\begin{array}{l}\text { importância do conteúdo que aprende } \\
\text { Motivação quando o processo de aprendizagem } \\
\text { possibilita uma experiência prazerosa }\end{array}$ & 0 & 4 & 56 \\
\hline
\end{tabular}

Fonte: Pesquisa (2014)

No que concerne aos aspectos motivacionais para aprendizagem, os resultados também não fogem do que se defende na abordagem andragógica, já que os sujeitos dessa pesquisa, enquanto alunos adultos, ratificaram que a motivação para a aprendizagem está associada à contribuição do aprendizado para a sua vida (Knowles; Holton \& Swanson, 2011; Rogers, 2011; Dewey, 1973).

Por fim, é pertinente destacar que os cursos de ensino superior, em geral, possuem um formato engessado. Assim, mesmo os alunos possuindo autonomia e maturidade, ficam restritos ao que o sistema impõe. Nesse sentido, destaca-se a importância da utilização de uma metodologia que possibilite abertura para os alunos adequarem seu processo de aprendizagem a sua forma particular de estudar e aprender. Mais uma vez é pertinente ressaltar a importância da utilização de estratégias de ensino voltadas à ação, considerando que essas estratégias permitem que os alunos relacionem a teoria e a prática, além de proporcionar que esses tenham uma atuação mais ativa em seu processo de aprendizagem.

\section{CONSIDERAÇÕES FINAIS}

O desenvolvimento do autodirecionamento além de otimizar o processo de aprendizagem, contribui positivamente na atuação profissional desses aprendizes enquanto gestores e 
planejadores do turismo e da hotelaria, considerando que os mesmos ao exercerem a sua profissão tomarão decisões em diversas situações, nas quais se farão necessárias atitudes como iniciativa e autonomia. Portanto, o ensino superior em turismo e em hotelaria deve promover condições libertadoras para impulsionar a autonomia e desenvolver um senso de autocapacitação. Como resultado terá alunos aptos a interagir no meio social, compreender o mundo, e interferir na realidade que o cerca (Mezirow, 1991; Freire, 1987).

Conforme sugere Freire (1987) é preciso criar condições para que as pessoas possam agir livremente, refletir, escolher e perceber as consequências das escolhas com o propósito de melhorar suas trajetórias. Assim, a utilização de estratégias de ensino como a resolução de casos ou a participação em simulações e jogos empresariais, dentre outras atividades voltadas à ação, são bastante pertinentes no ensino superior em turismo e hotelaria. O uso de estratégia de ensino em ação, de acordo com Lima (2011), pode tornar esses alunos mais capacitados ao ingressar nas organizações e capazes de resolver os problemas em tempo real por meio do elo entre reflexão e ação.

É pertinente ressaltar que a seleção da atividade de ensino deve estar associada às capacidades que se deseja estimular nos alunos. As técnicas de ensino devem ser selecionadas com base nos objetivos de ensino (objetivos educacionais), no tipo de alunos a que se destinam (características dos alunos), na matéria e no momento em que a técnica será desenvolvida. Destaca-se ainda a observância de medidas como a qualidade do material didático, a estruturação das salas de aula, as avaliações planejadas e continuadas, e feedbacks para se atingir o bom desenvolvimento de uma disciplina, ajudando a estimular a atitude autônoma e autodirecionada dos aprendizes.

Com os resultados desse estudo fica o convite a todos os agentes envolvidos no desenvolvimento de cursos superiores - não apenas dos cursos de turismo e hotelaria, para refletirem sobre as estratégias de ensino e recursos utilizados no processo de aprendizagem nas universidades, com atenção aos fatores mediadores que causam interferências na aprendizagem. Os princípios andragógicos abordados no estudo destacam que o aluno do ensino superior possuem características como autonomia, autodirecionamento e apresentam níveis de independência enquanto sujeitos em processo de formação e de desenvolvimento de competências, o que revela a necessidade de pensar a formação profissional não apenas a partir de uma dimensão técnica, mas também considerar que o curso contribui para a formação de cidadãos que vão atuar não apenas no contexto profissional, como podem gerar impactos no contexto social.

Por fim, é pertinente ressaltar que os resultados desse estudo apresentam apenas a percepção dos próprios alunos sobre sua atuação em seu processo de aprendizagem. Nesse sentido, a realização de um estudo semelhante cujos dados sejam coletados com os professores podem trazer outras constatações ampliando o entendimento sobre o processo de aprendizagem de discentes de turismo e hotelaria. 
Além disso, somada a interferência dos fatores mediadores associados às características individuais do aprendiz adulto, existem ainda outros aspectos que merecem atenção. Embora não tenham sido objeto dessa pesquisa, é possível observar que a educação de adultos possui ainda fatores mediadores contextuais, tais como a metodologia e as estratégias de ensino utilizadas nos cursos, os recursos utilizados no processo de aprendizagem, aspectos institucionais, a relação do aluno com o professor, entre outros, que podem está sendo observados em estudos subsequentes.

\section{REFERÊNCIAS}

Argyris, C. (1982). Reasoning, learning and action: individual and organizational. San Francisco: Jossey-Bass. Brookfield, S. D. (1986). Understanding and Facilitating Adult Learning: a comprehensive analysis of principles and effective practices. San Francisco: Jossey-Bass.

Brusadin, L. B. (2007). A formação do bacharel em turismo com base nas estruturas curriculares e nos docentes dos cursos de graduação. Estudo de casos: Universidade de Espírito Santo do Pinhal e Universidade de Franca. Anais do IV Seminário da Associação Brasileira de Pesquisa e Pós-Graduação em Turismo. UAM - 27 a 28 de agosto de 2007.

Candy, P. C. (1991). Self direction for lifelong learning: a comprehensive guide to theory and practice. San Francisco (USA): Jossey-Bass.

Candy, P. C. (1987) Reframing research into 'self-direction' in adult education: A constructivist perspective. Doctoral dissertation, University of British Columbia. Ottawa: National Library of Canada, Canadian Theses (Microfiche: 0-315-40011-0).

Carneiro, A. L. M. (2002). O olhar dos egressos do curso superior de tecnologia em hotelaria sobre sua formação. 118p. Dissertação (Mestrado) - Pontifícia Universidade Católica de São Paulo. São Paulo.

Cavalcanti, R. A; Gayo, M. A. F. (2005). Andragogia na educação universitária. Conceitos. Julho.

Chene, A. (1983). The concept of autonomy in adult education: A philosophical discussion. Adult Education Quarterly, n 1, pp. 38-47.

Couceiro, M. L. (1995). Autoformação e contexto profissional. Formar, Instituto do Emprego e Formação Profissional, n 14, pp. 6-15.

Cranton, P. (2006). Understanding and Promoting Transformative Learning. A Guide for Educators of Adults. Second Edition. San Francisco: Jossey-Bass.

Dewey, J. (1973). Vida e Educação. Comp. Melhoramentos de São Paulo. Indústria de Papel Caixa Postal, 8120.Tradução Anísio S. Teixeira. São Paulo.

Ferraz, S. F. S.; Lima, T. C. B. \& Silva, S. M. O. (2004). Contratos de aprendizagem: Princípios andragógicos e ferramenta de gestão da aprendizagem. In: ENCONTRO DA ASSOCIAÇÃO NACIONAL DE PROGRAMAS DE PÓS-GRADUAÇÃO EM ADMINISTRAÇÃO-ENANPAD, 28, Salvador. Anais..., Salvador: ANPAD, 2004. 1 CDROM. 
FONSECA, J. J. S.(2002). Metodologia da pesquisa científica. Fortaleza: UEC, 2002. Apostila.

Freire, P. (2003). Pedagogia da Autonomia - saberes necessários à prática educativa. Rio de Janeiro: Paz e Terra.

Freire, P. (1987). Pedagogia do oprimido. 27 ed. Rio de Janeiro: Paz e Terra.

Garrison, D. R. (1992). Critical thinking and self-directed learning in adult education. Adult Education Quartely, 2, 102-116.

James-Gordon, Y.; Young, A. \& Bal, J. (2003). External environment forces affecting e-learning providers. Marketing Intelligence \& Planning, v.21, n.3.

Jarvis, P. (2006). Towards a Comprehensive Theory of Human Learning: lifelong Learning and the learning society. New York: Routledge.

Knowles, M. S, Holton, E. F. \& Swanson, R. A. (2011). The adult learner: The definitive classic in adult education and human resource development - 7th edition. London: Elsevier.

Knowles, M. S. (1980). The modern practice of adult education: from pedagogy to andragogy. Cambridge: Adult Education.

Knowles, M. S. (1975) Self-directed learning: A guide for learners and teachers. Englewood Cliffs: Prentice Hall/Cambridge.

Kolb, D. (1984). Experiential Learning: Experience as The Source of Learning and Development. Prentice Hall, New Jersey.

Lima, T. B (2011). Estratégias de Ensino Balizadas pela Aprendizagem em Ação: um estudo no de Graduação em Administração na Universidade Estadual da Paraíba. Dissertação de Mestrado.

Merriam, S. B., Caffarella, R. S., \& Baumgartner, L. M (2006). Learning in adulthood (3rd ed.). San Francisco: John Wiley \& Sons.

Mezirow, J. (1985). A critical theory of self-directed learning. In S. Brookfield (Ed.), Self-directed learning: from theory to practice. San Francisco: Jossey-Bass, 17-30.

Mezirow, J. (1991). Learning to Think Like an Adult: core concepts of transformative learning. In: Mezirow, J. et al. Learning as Transformation: critical perspectives on a Theory in progress. San Francisco: JosseyBass.

Rogers, C.R. (1969). Freedom to Learn. Columbus, OH: Merrill.

Rogers, J. (2011). Aprendizagem de adultos: fundamentos para educação corporativa. Porto Alegre: Artmed.

Schön, D. (1987). Educating the reflective practitioner. Toward a new design for teaching and learning in the professions. San Francisco: Jossey-Bass. 
Silva, A. B (2009). Como os gerentes aprendem?. São Paulo: Saraiva.

Silva, A. C. R. (2005). Abordagem Curricular por Competências no Ensino Superior: um estudo exploratório nos Cursos de Administração, Ciências Contábeis e Economia no estado da Bahia - Brasil. 2005. 433f. (Tese de Doutorado). Ciência da Educação, na área de Desenvolvimento Curricular, na Universidade do Minho.

Silva, A. B.; Godoi, C. K. \& Rambo, J. A. M. (2003). Fatores Individuais e Organizacionais Associados a Aprendizagem dos Gerentes de uma Instituição de Ensino. X Seminário Latino-Iberoamericano de Gestión Tecnológica ALTEC.

Smith, M. K (2002). Malcolm Knowles, informal adult education, self-direction and andragogy. In the encyclopedia of informal education. Disponivel em: www.infed.org/thinkers/et-knowl.htm. Acesso em: 31 de ago.

Souza, Y. S. (2004). Organizações de Aprendizagem ou Aprendizagem Organizacional. RAE-Eletrônica Revista de Administração de Empresas, v.3, n.1, Art.5, Jan/Jun.

Artigo recebido em: 15/05/2014. Artigo aprovado em: 25/11/2014 